\title{
PERCUTANEOUS CT GUIDED FNAC OF LUNG MASSES: EXPERIENCE AT A TERTIARY MEDICAL CENTRE
}

Reena Kouli1, Aparna Dutta ${ }^{2}$, Samrat Bhattacharjee ${ }^{3}$

${ }_{1}^{1}$ Associate Professor, Department of Pathology, Assam Medical College, Dibrugarh.

${ }^{2}$ Assistant Professor, Department of Pathology, Assam Medical College, Dibrugarh.

${ }^{3}$ Demonstrator, Department of Pathology, Assam Medical College, Dibrugarh.

\section{ABSTRACT}

\section{BACKGROUND}

The diagnosis of a lung mass is possible by utilizing cytological analysis of the tissue obtained by Fine Needle Aspiration Cytology (FNAC). With the development of Computed Tomography (CT) guided FNAC, the safety and accuracy of the procedure has also improved. Although this modality of investigation shows wide variation in sensitivity and specificity, but its role in the investigation of a lung mass is quite well established. The aim of this study was to evaluate the effectiveness of CT-guided FNAC in patients presenting with lung masses and the patterns of diagnosis in such patients.

\section{MATERIALS AND METHODS}

The study was carried out over a two-year period in the Department of Pathology of a Tertiary Medical Centre of North-East India. It involved 58 patients who underwent CT guided FNAC for lung masses. After obtaining an informed consent, the procedure was performed and the obtained material was processed, evaluated and finally diagnosed by a cytopathologist.

\section{RESULTS}

A total of 58 patients were studied. Majority (77.6\%) of the patients were male. The diagnostic accuracy of the procedure was $77.59 \%$. Among the diagnosed cases, $82.2 \%$ cases were malignant. Squamous cell carcinoma was the commonest malignancy (56.7\%) followed by Adenocarcinoma (37.8\%). One case each of Small cell carcinoma and Large cell carcinoma was detected. Benign inflammation was seen in $13.8 \%$ of the diagnosed cases.

\section{CONCLUSION}

CT guided FNAC is a vital tool in the diagnostic workup of lung masses, because of its safety and reliability and thus it helps in the early management of patients.

\section{KEYWORDS}

CT Guided FNAC, Lung Mass, Squamous Cell Carcinoma, Adenocarcinoma, Small Cell Carcinoma.

HOW TO CITE THIS ARTICLE: Kouli R, Dutta A, Bhattacharjee S. Percutaneous CT guided FNAC of lung masses: experience at a tertiary medical centre. J. Evolution Med. Dent. Sci. 2016;5(34):1892-1895, DOI: 10.14260/jemds/2016/447

\section{INTRODUCTION}

The use of a needle to aspirate tissue from a lesion lying superficially or in a deeper organ and studying it under a microscope has been known for quite some time, but the use of Fine Needle Aspiration Cytology (FNAC) as a diagnostic tool was first started by Martin and Ellis in the 1930's.[1] It is a simple and safe investigation, which gives highly reliable results in a short span of time and helps in early clinical management. With the advent of Computed Tomography (CT) scan, FNAC has become an even better modality because of real time visualization of the approaching needle and the target lesion. Lung is a common site for many benign, malignant and infectious lesions and they can be accurately diagnosed using FNAC.

Financial or Other, Competing Interest: None.

Submission 09-03-2016, Peer Review 05-04-2016,

Acceptance 11-04-2016, Published 27-04-2016.

Corresponding Author:

Dr. Reena Kouli,

Associate Professor,

Department of Pathology,

$1^{\text {st }}$ Floor Basic Science Building,

Assam Medical College \& Hospital,

Dibrugarh-786002

Assam.

E-mail: koulir@gmail.com

DOI: $10.14260 /$ jemds $/ 2016 / 447$
Its use has been extended in differentiating lung malignancy into different cytopathological types, which aids in proper management of the malignant lesion.[2] CT guided FNAC of lung was first described in 1976.[3] It has become an established diagnostic procedure with excellent results worldwide and although pneumothorax is the most common complication it can be readily managed.[2]

The following study was done over a two-year period at a teaching hospital of North-East India to evaluate the usefulness of CT guided FNAC in the diagnosis of lung masses.

\section{MATERIALS AND METHODS}

It is a hospital-based descriptive study and was carried out in the Department of Pathology of a Tertiary Medical Centre over a two-year period from January 2013 to January 2015 with approval from the Institution Ethics Committee. A total of 58 cases underwent CT guided FNAC during this period. A detailed informed consent was obtained from every patient. All relevant clinical history and previous investigations were duly noted.

Any history of bleeding disorders, vascular anomalies, pulmonary hypertension, severe chronic obstructive pulmonary disease or severe intractable cough was ruled out in all the patients undergoing the procedure.

After obtaining due permission from the patient, he/she was made to lie down on the CT table. The position of the 
patient was supine, lateral or prone depending on the location of the pulmonary mass of interest. All aseptic precautions were followed and the area of skin to be punctured was cleaned with povidone iodine properly. Then a 20 -gauge spinal needle was introduced percutaneously and its approach was tracked by CT scan. When the target was reached, the stylet was removed and a $10 \mathrm{~mL}$ or $20 \mathrm{~mL}$ syringe was attached to the needle. By applying negative suction, aspirate was obtained by to and fro and rotating movements of the needle within the lesion.

The needle was withdrawn and the aspirated material was collected in 3 to 5 slides. If the aspirated material was judged to be inadequate, then the procedure was repeated. A maximum of two needle passes was allowed in a patient. The slides were air dried and taken to the cytopathology lab for staining with May Grunwald Giemsa (MGG). The patient was observed and a repeat CT scan of the chest was taken postprocedure to rule out pneumothorax or any other complication.

All the relevant data was duly collected and properly analysed.

\section{RESULTS AND OBSERVATIONS}

A total of 58 cases underwent CT guided FNAC of lung during the duration of the study; 45 patients were male $(77.6 \%)$ and 13 patients were female (22.4\%).

\begin{tabular}{|c|c|}
\hline Age Group (In Years) & No. of Patients \\
\hline $10-30$ & 4 \\
\hline $31-50$ & 15 \\
\hline $51-70$ & 33 \\
\hline$>70$ & 6 \\
\hline Total & 58 \\
\hline Table 1: Age Distribution of Patients \\
\hline
\end{tabular}

The youngest patient in our study was 19 years old and the oldest was 90 years old. The majority of the patients $(n=33)$ were in the age group of 51-70 years and the mean age was calculated as 55.19 years.

\section{Diagnostic Accuracy}

A total of 58 patients were subjected to CT guided FNAC in our study, and out of them a cytological diagnosis could be given in 45 cases; 13 cases (22.4\%) could not be diagnosed either due to inadequate amount of sample or absence of diagnostic elements. The diagnostic accuracy rate was thus $77.59 \%$.

\section{Cytological Diagnosis}

A definitive cytological diagnosis could be given in 45 cases out of the 58 patients undergoing CT guided FNAC. The diagnosis of patients were grouped according to the following categories-

A. Malignant (Total=37)

a. Squamous cell carcinoma

b. Adenocarcinoma

21

c. Large cell carcinoma

d. Small cell carcinoma

14

1

1

C. Benign inflammation (Total $=8$ )

a. Non-specific inflammation

b. Granulomatous inflammation

Thus, in the present study 37 of the 45 diagnosed cases were cytologically malignant (82.2\%). Among the cases which could be cytologically subtyped, the most common malignancy was Squamous cell carcinoma (21 out of 37 cases, $56.7 \%$ ). Adenocarcinoma was second commonest (14 out of 37 cases, $37.8 \%$ ), and only one case each of Large cell carcinoma and Small cell carcinoma was seen.

Benign inflammation comprised 8 of the 58 cases (13.8\%); 7 cases were reported as non-specific inflammation and only one case of granulomatous inflammation (ZiehlNeelsen stain negative) was seen.

Unfortunately, histopathological confirmation could not be obtained in majority of the cases as HPE samples were unavailable.

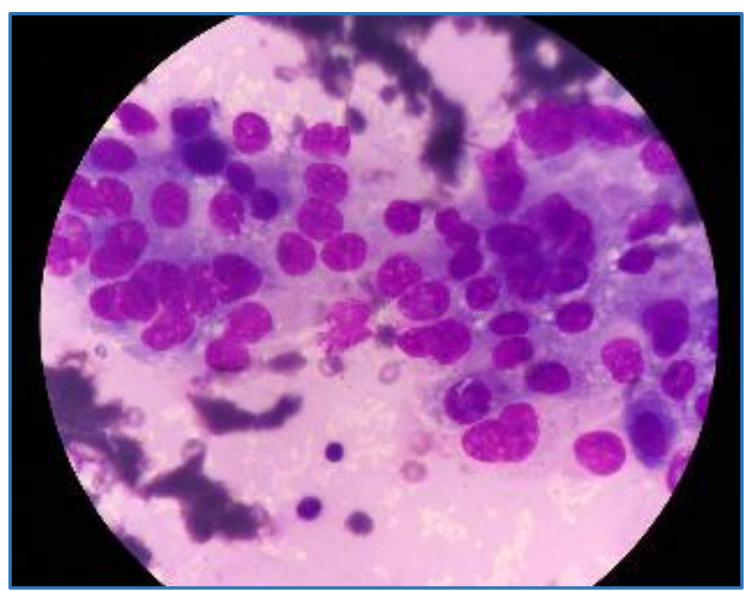

Fig. 1: Adenocarcinoma (MGG, 100x)

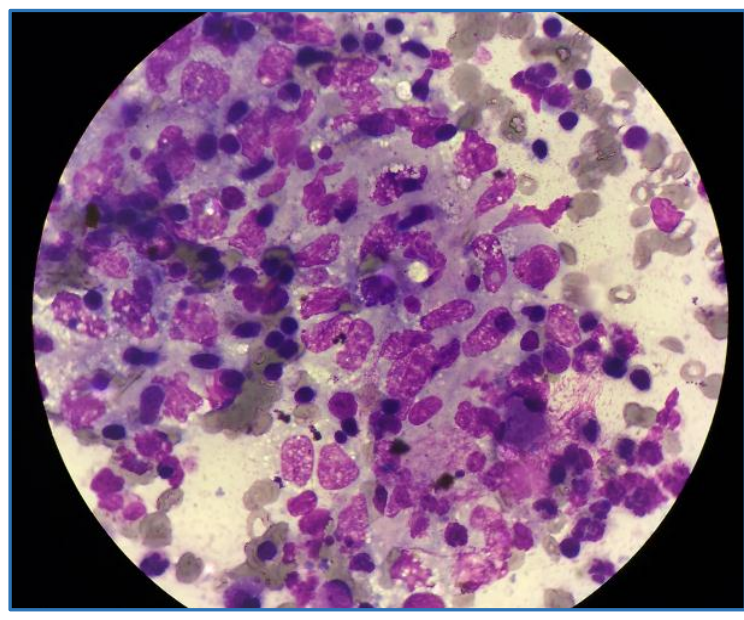

Fig. 2: Granulomatous Inflammation (MGG, 100x)

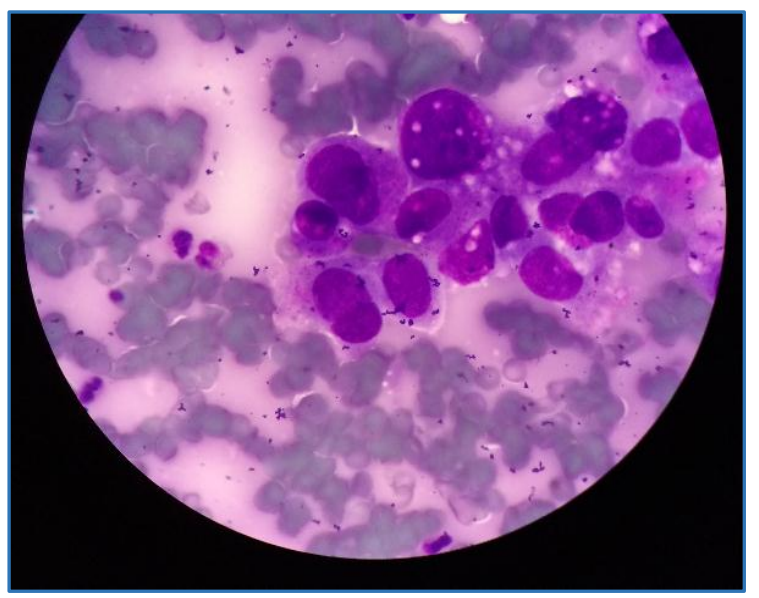

Fig. 3: Large Cell Carcinoma (MGG, 100x) 


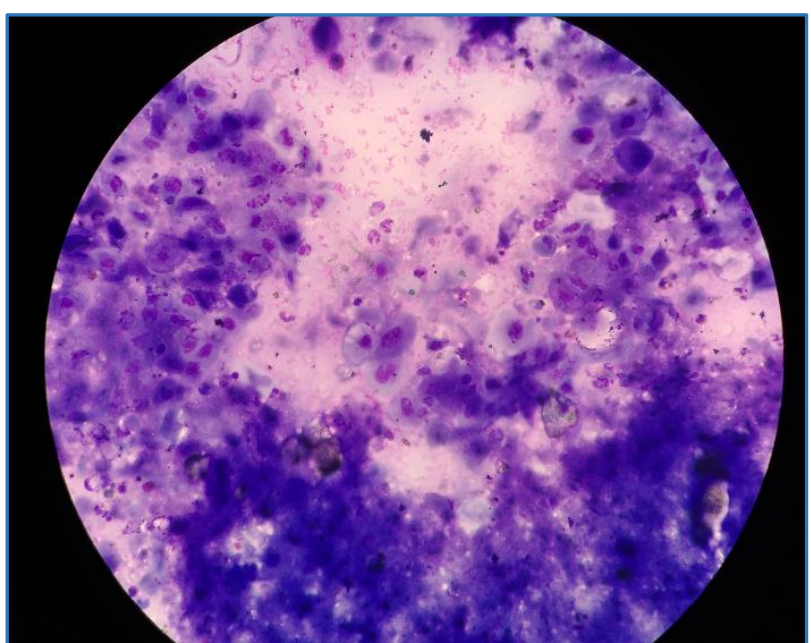

Fig. 4: Squamous Cell Carcinoma (MGG, 100x)

\section{DISCUSSION}

Although, FNAC of a lung lesion was described way back in 1886.[4] CT guided FNAC of lungs was first described by Haaga and Alfidi in 1976.[3] The procedure is highly useful because of its high sensitivity in detecting malignant lesions and subtyping of the lesion. A specific benign diagnosis reduces the incidence of surgery and the resultant morbidity in many cases.[5]

In our study, 58 patients underwent CT guided FNAC of lung lesions. A significant majority of the patients were male $(77.6 \%)$. Saha et al also showed a significant male predominance.[6] but other larger studies have shown a lower degree of such predominance. ${ }^{[2,4]}$ The majority of cases were seen in the fifth to seventh decade and had a mean age of 55.19 years, which agrees with the observations of a few recent studies done in East India.[2,7]

FNAC was diagnostic in 45 out of 58 cases, providing a diagnostic accuracy of $77.59 \%$, which is close to the findings of a few studies. ${ }^{[8,9,10]}$ whereas a few other authors have found a higher rate of accuracy.[11,12] In an analysis of multiple studies, the adequacy of samples obtained by lung FNAC has been reported to be between $80 \%-95 \% .[13]$ A number of factors affect the final outcome of FNAC, starting from the performance of the procedure to the final interpretation by a cytopathologist. The patient related factors include the location and size of the lesion and the degree of necrosis.[14] During the sampling, the important factors are the size of the needle used and its proper positioning within the lesion, the amount of material aspirated and the quality of smear preparation and staining. The experience and knowledge of the cytopathologist is a major factor in reaching a diagnosis in the end. With development in the field of immunecytochemistry it is now possible to give a definitive diagnosis from cytological samples, but it warrants additional material during sampling and needs a specialized setup. ${ }^{[4]}$

In our study, $82.2 \%$ of the diagnosed cases were malignant. Our findings are in agreement with the observations of Arslan et al[10] and Gangopadhyay et al[15], but few others have shown a lower rate of malignant diagnosis.[16,17] There has been a significant increase in the incidence of adenocarcinoma worldwide recently.[18], but few studies have shown increased percentage of Squamous cell carcinoma. $[6,10,17]$ as well.
Among the malignant cases, Squamous cell carcinoma was the commonest in our study $(56.7 \%)$. The incidence of Small Cell Lung Carcinoma (SCLC) has been reported to be around $20 \% .{ }^{[19]}$ but only one case of SCLC $(1.72 \%)$ was seen in the present study.

This wide discrepancy may be due to the small sample size of our study or due to procedural deficiencies.

Benign inflammation was reported in $13.8 \%$ of the diagnosed cases, which is similar to the findings of a few earlier studies.[2,10] Among these, only one case of granulomatous inflammation (ZN stain negative) was seen.

In $22.4 \%$ cases, the material was inadequate for giving a cytological diagnosis. This figure is quite high as compared to the observations of most studies. [10,15,17], but Basnet et al[20] did observe a high rate of inadequate sampling (18\%). As discussed earlier, a number of factors are involved in reaching a conclusive diagnosis by FNAC and a deficiency in any of those steps can lead to a fallacious or inconclusive diagnosis. The high rate of inadequacy in our study may be explained by the low sample size, shorter duration of the study and factors related to the procedure itself.

\section{CONCLUSION}

Among all malignancies, lung cancer causes significant mortality and morbidity worldwide, hence its diagnosis is of paramount importance. The status of FNAC in the diagnostic workup of a lung mass is well established. With the advent of CT guided FNAC, it has become a safe, reliable and quick method of diagnosis in such patients. A cytological diagnosis is considered provisional in many cases, but it helps the clinician in selecting the best course of action for the patient. The results of our study compare well with other studies from other parts of the world, confirming the importance of this vital mode of investigation in our region.

\section{REFERENCES}

1. Martin H, Ellis E. Biopsy by needle puncture and aspiration. Ann Surg 1930;92(2):169-81.

2. Mondal S, Nag D, Osta $\mathrm{M}$, et al. Computed tomogram guided fine-needle aspiration cytology of lung mass with histological correlation- a study in eastern India. South Asian Journal of Cancer 2013;2(1):14-8.

3. Haaga J, Alfidi R. Precise biopsy localization by computed tomography. Radiology 1976;118(3):603-7.

4. Kravtsov V, Sukmanov I, Yaffe D, et al. Diagnostic aspects of fine needle aspiration for lung lesions-series of 245 cases. Asian Pacific Journal of Cancer Prevention 2014;15(22):9865-9.

5. Haramati L, Austin J. Complications after CT-guided needle biopsy through aerated versus nonaerated lung. Radiology 1991;181(3):778.

6. Saha A, Kumar K, Choudhuri M. Computed tomographyguided fine needle aspiration cytology of thoracic mass lesions-A study of 57 cases. Journal of Cytology 2009;26(2):55-9.

7. Sumana M, Gautam B, Aparna B, et al. Computed tomography-guided fine needle aspiration cytology of solitary pulmonary lesions suspected to be bronchogenic carcinoma-experience of a general hospital. Journal of Cytology 2010;27(1):8-11. 
8. Beslic S, Zukic F, Milisic S. Percutaneous transthoracic CT guided biopsies of lung lesions-fine needle aspiration biopsy versus core biopsy. Radiology and Oncology 2012;46(1):19-22.

9. Singh JP, Garg L, Setia V. Computed tomography (CT) guided transthoracic needle aspiration cytology in difficult thoracic mass lesions-not approachable by USG. Indian Journal of Radiology and Imaging 2004;14(4):395-400.

10. Arslan S, Yilmaz A, Bayramgurller B, et al. CT guided fine needle aspiration of pulmonary lesions-accuracy and complications in 294 patients. Medical Science Monitor 2002;8(7):493-7.

11. Poulou L, Tsagouli P, Ziakas P, et al. Computed tomography-guided needle aspiration and biopsy of pulmonary lesions: a single-center experience in 1000 patients. Acta Radiol 2013;54(6):640-45.

12. Rangaswamy M, Krishnamurthy J, Zacharia T, et al. Study of computed tomography guided fine needle aspiration cytology of thoracic lesions. Journal of Cytology 2012;29(1):30-4.

13. Zarbo RJ, Fenoglio-Preiser CM. Interinstitutional database for comparison of performance in lung fineneedle aspiration cytology a college of American pathologists Q-probe study of 5264 cases with histologic correlation. Arch Pathol Lab Med 1992;116(5):463-70.

14. Hiraki T, Mimura H, Gobara H, et al. CT fluoroscopyguided biopsy of 1,000 pulmonary lesions performed with 20-gauge coaxial cutting needles: diagnostic yield and risk factors for diagnostic failure. Chest 2009;136(6):1612-7.
15. Gangopadhyay M, Chakrabarti I, Ghosh N, et al. Computed tomography guided fine needle aspiration cytology of mass lesions of lung-our experience. Indian Journal of Medical and Paediatric Oncology 2011;32(4):192-6.

16. Tan KB, Thamboo TP, Wang SC, et al. Audit of transthoracic fine needle aspiration of the lungcytological subclassification of bronchogenic carcinomas and diagnosis of tuberculosis. Singapore Med J 2002;43(11):570-5.

17. Konjengbam R, Singh N, Gatphoh S. Computed tomography guided percutaneous transthoracic fine needle aspiration cytology of pulmonary mass lesionstwo years cross sectional study of 61 cases. Journal of Medical Society 2014;28(2):112-6.

18. De Groot P, Munden RF. Lung cancer epidemiology, risk factors, and prevention. Radiology Clinics of North America 2012;50(5):863-76.

19. Wu X, Groves FD, McLaughlin CC, et al. Cancer incidence patterns among adolescents and young adults in the United States. Cancer Causes Control 2005;16(3):30920.

20. Basnet SB, Thapa GB, Shahi R, et al. Computed tomography guided percutaneous transthoracic fine needle aspiration cytology in chest masses. Journal of Nepal Medical Association 2008;47(171):123-7. 